\title{
Dicionário Colaborativo de Libras
}

\section{José Eduardo Brandão ${ }^{1}$, Carla Diacui Medeiros Berkenbrock ${ }^{1}$, Eric Silveira ${ }^{1}$, Gian Ricardo Berkenbrock ${ }^{2}$}

\author{
${ }^{11}$ Universidade do Estado de Santa Catarina (UDESC) \\ Joinville - SC - Brasil \\ ${ }^{2}$ Universidade Federal de Santa Catarina \\ Joinville - SC - Brasil \\ brandaozeh@gmail.com, carla.berkenbrockeudesc.br, \\ eric.cvsilveira@gmail.com, gian.rb@ufsc.br
}

\begin{abstract}
According to the 2010 Census conducted by IBGE, 9.7 million people have hearing impairment. However, only in 2002, through Law no. 10.436, that the Brazilian Sign Language (Libras) was recognized as the second offcial language in Brazil. Therefore, this part of the population faces several accessibility problems, which are aggravated by the lack of tools that help deaf people in common everyday tasks. Thus, the purpose of this work is to develop a collaborative dictionary of the Brazilian Sign Language so that speaking users and Libras learners can collaborate in the signs feeding. The dictionary aims to contemplate regionalism, as well as to provide parameters that structure the formation of Libras at different linguistic levels.
\end{abstract}

Resumo. Segundo o Censo de 2010 realizado pelo IBGE, 9,7 milhões de pessoas têm deficiência auditiva. Contudo, somente em 2002, através da Lei $n$. 10.436, que a Língua Brasileira de Sinais (Libras) foi reconhecida como segunda língua oficial no Brasil. Diante disso, essa parte da população enfrenta diversos problemas de acessibilidade, sendo estes agravados pela falta de ferramentas que auxiliem as pessoas surdas em tarefas comuns do dia a dia. Deste modo, a proposta deste trabalho é desenvolver um dicionário colaborativo da Língua Brasileira de Sinais para que usuários falantes e aprendizes de Libras consigam colaborar na alimentação de sinais. O dicionário visa contemplar o regionalismo, bem como fornecer parâmetros que estruturam a formação da Libras nos diferentes níveis linguísticos.

\section{Introdução}

O Brasil, além da Língua Portuguesa, possui como língua oficial a Língua Brasileira de Sinais (Libras), sendo esta adotada como primeira língua por grande parcela dos surdos e deficientes auditivos no país. As diferenças entre as estruturas sintáticas e morfológicas da Língua Portuguesa e da Língua Brasileira de Sinais provocam barreiras na comunicação (MOURA, 2015). Isso pode tanto dificultar quanto impossibilitar que as pessoas surdas desempenhem tarefas cotidianas, como fazer compras, pedir informações ou realizar movimentações bancárias.

Ressalta-se que a comunidade surda não é composta apenas por sujeitos surdos, mas também pelos ouvintes, sendo estes membros da família, intérpretes, professores, 
amigos e outros que participam e compartilham interesses comuns em uma determinada localização (STROBEL, 2016). Essa comunidade é de grande importância para a disseminação da língua de sinais, dado que, quanto mais indivíduos forem falantes de Libras, maior será a inclusão de pessoas surdas na sociedade, o que possibilitará o desenvolvimento de novos materiais e ferramentas sobre o assunto.

Tecnologias específicas para solucionar conflitos decorrentes da comunicação estão sendo desenvolvidas a fim de contribuir com os processos cotidianos das pessoas surdas, como por exemplo, a ferramenta iLibras (COSTA et al., 2017). Outro exemplo de ferramenta é o VLibras (SUITE..., 2017), que permite a tradução automática de conteúdos digitais (texto, áudios e vídeos) para Libras. O Dicionário da Língua Brasileira de Sinais V3 - 2011 (LIRA; SOUZA, 2011), criado a fim de auxiliar surdos ou ouvintes que buscam aprimorar ou aprender termos em Libras, é a ferramenta que despertou o interesse pelo desenvolvimento deste trabalho. Nessa ferramenta, o usuário faz a pesquisa do termo dentro do dicionário e então consegue o resultado do sinal por vídeo. Além do sinal, o termo pesquisado é exemplificado em uma frase que amplia a visão do usuário para o seu entendimento. Contudo, ao analisar esse dicionário, é possível identificar limitações, como por exemplo, a falta de regionalismo. Destaca-se que o regionalismo, ou variação linguística, é o resultado da influência histórica de cada geração e seus acontecimentos gerados por meio da língua pela sociedade. A língua tem o fator de evolução e essas evidências podem ser vistas nas variações, tanto pela história, região e sociedade. Em Libras existem vários sinais com o mesmo significado e esses são diretamente influenciados pela variação social e ocorrências da região (OLIVEIRA; MARQUES, 2014). O regionalismo está presente em Libras, assim como em qualquer outra língua (FREITAS; BERKENBROCK; SELL, 2019). Outra adaptação importante da ferramenta é o fornecimento de parâmetros que auxiliem o usuário a compreender a gramática de Libras acerca da palavra buscada.

A gramática da Língua Brasileira de Sinais tem sua estrutura gramatical organizada a partir de alguns parâmetros, tais como parâmetros primários e secundários e componentes não-manuais. Os parâmetros primários são compostos pela configuração da mão (a forma que a mão assume na realização de um sinal), ponto de articulação (lugar onde o sinal é realizado) e movimento que as mãos realizam no espaço sobre o corpo. Além disso, temos os parâmetros secundários que possuem como informação a disposição e orientação das mãos e região de contato. E, por último, os componentes não-manuais que são caracterizados pela expressão facial ou movimento do corpo, que podem definir ou diferenciar significados entre sinais.

Ante o exposto, o presente trabalho trará o desenvolvimento de um dicionário colaborativo para que usuários falantes e aprendizes de Libras consigam colaborar na alimentação de sinais. O dicionário visa contemplar o regionalismo e a gramática de Libras, visto que ainda existe uma lacuna na exploração desses conceitos nas ferramentas atuais voltadas para a comunidade surda.

\section{Trabalhos Relacionados}

Alguns trabalhos já foram desenvolvidos na linha de comunicação com sujeitos surdos. Costa et al. (2017) apresenta o iLibras, uma ferramenta computacional móvel e 
colaborativa voltada para facilitar a comunicação efetiva do surdo. A ferramenta apresenta diversos conteúdos: o usuário pode realizar a busca da palavra na língua portuguesa textual e tem como resultado um vídeo em Libras com legenda em português, a palavra descrita em escrita de sinais (signwriting), e uma imagem representativa da palavra.

Lira e Souza (2011) apresentam o Dicionário da Língua Brasileira de Sinais, uma ferramenta para a busca de traduções de palavras em Libras. Nela são apresentados diversos conteúdos para a palavra buscada: assuntos, a orientação de mão, um video da palavra traduzida por um intérprete, a acepção, exemplos da palavra em uma frase em português e em linguagem adaptada para surdos, sua classe gramatical e origem, e por fim uma imagem da palavra buscada. A avaliação e análise da ferramenta foi realizada por Freitas, Berkenbrock e Sell (2019), onde foi concluído que a falta de colaboração é um fator negativo da ferramenta, visto que assim ela se torna estática por não possibilitar seus usuários adicionarem novos sinais. Além disso, a ferramenta não contempla o regionalismo.

O Senai Libras busca ensinar termos da educação profissional para sujeitos surdos. Em matéria do jornal Estadão (VENTURA, 2021), afirma-se que o software complementa aulas presenciais e foi validado por diversos usuários surdos. A ferramenta funciona como um dicionário onde o usuário pode buscar a palavra desejada a partir da língua portuguesa textual. O resultado aparece junto com uma imagem figurativa, além de poder sugerir novos verbetes a serem adicionados à ferramenta. Assim que a palavra é selecionada são apresentados três conteúdos para o usuário: (i) uma animação $3 \mathrm{~d}$ de um intérprete virtual que traduz a palavra buscada, podendo variar sua velocidade de reprodução; (ii) uma apresentação de passo a passo na língua portuguesa textual para fazer o gesto da palavra desejada em Libras; (iii) o significado da palavra no contexto da educação profissional.

A semelhança dos trabalhos correlatos com a presente pesquisa é que todos apresentam a tradução da palavra, seja por vídeo ou tradutor virtual. O que se difere é que a presente pesquisa prevê a colaboração entre os usuários para adição e avaliação dos sinais, além de contemplar o regionalismo. A proposta do presente trabalho também busca considerar os diferentes tópicos gramaticais das palavras em Libras, como a configuração de mãos, o ponto de articulação, o movimento, a disposição de mãos, a orientação das mãos e a região de contato.

\section{Questões Gramaticais}

Assim como as línguas faladas, a Libras também possui gramática. Sua composição é dividida em três categorias principais: os parâmetros primários, os parâmetros secundários e os componentes não-manuais. Os parâmetros primários representam: (i) a configuração das mãos, que define a forma que a mão assume na realização de um sinal; (ii) o ponto de articulação, que indica o lugar onde é realizado o sinal. Os sinais realizados em contato ou próximo a determinadas partes do corpo, pertencem muitas vezes a um campo semântico específico a partir de características icônicas. O que se refere a sentimentos, perto do coração e que refere à raciocínio perto da cabeça; (iii) o movimento dos gestos, que indica o deslocamento da mão no espaço na realização de um sinal, pode ser em linhas retas, curvas, sinuosas ou circulares, em várias direções e posições. 
Já os parâmetros secundários são formados por: (i) a disposição de mãos, que determina que os sinais de Libras podem ser feitos com a mão dominante ou ambas as mãos; (ii) a orientação das mãos, que indica a direção da palma durante a execução do sinal; (iii) a região de contato, que estabelece o local do corpo que deve ser feito o sinal. Um mesmo gesto pode ter diferentes significados quando realizado em regiões de contato distintas, como pode ser observado na Figura 1.

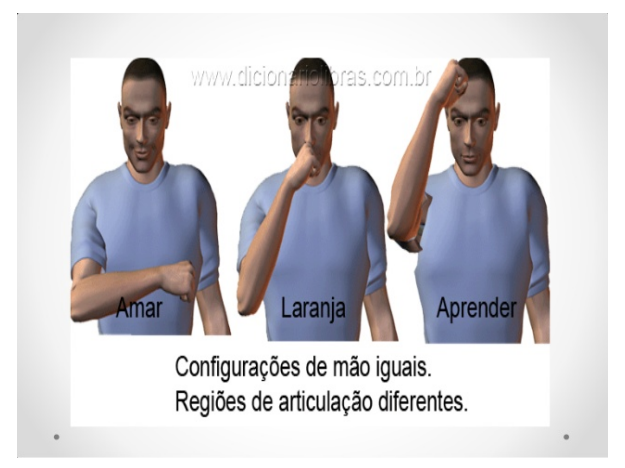

Figura 1. Fonte: Stock (2018)

Os componentes não-manuais são a expressão facial ou movimento do corpo, que muitas vezes podem definir ou diferenciar significados entre sinais. A expressão facial e corporal podem traduzir alegria, tristeza, raiva, amor, encantamento, entre outros sentimentos.

\section{O Sistema de Colaboração}

Esse trabalho se baseia no conceito do Modelo 3C de colaboração. Segundo Fuks et al. (2011), o Modelo 3C analisa colaboração em 3 dimensões: comunicação, coordenação e cooperação. A comunicação, caracteriza-se pela troca de mensagens, a coordenação pelo gerenciamento de pessoas e a cooperação pela atuação conjunta no espaço compartilhado.

Diante disso, a ferramenta delineada relaciona-se com o Modelo 3C de colaboração por intermédio da seguinte configuração: a coordenação será realizada por usuários administradores. Esses usuários dispõem de maior grau na hierarquia dentro da ferramenta, logo, possuem responsabilidades, tais como: coordenar tanto novas entradas de dados quanto dados já aprovados na ferramenta; coordenar usuários comuns e controlar a comunicação entre esses. Essas atividades trarão mais confiabilidade para os dados presentes e dificultará ações de usuários com más intenções. A comunicação será realizada de forma assíncrona por meio do feedback das ações do usuário dentro da ferramenta, como as avaliações dos sinais pelos usuários. Já a cooperação será o registro de todas formas de comunicação coordenadas pelos administradores em um espaço compartilhado, possibilitando que todos os usuários consigam obter estas informações e as utilize como forma de aprendizado em Libras. Essa forma de representação será utilizada para auxiliar a coordenação por parte dos usuários administradores a partir de novas inserções no sistema. Com isso, serão criadas histórias de usuário conforme o Framework $5 \mathrm{~W}+1 \mathrm{H}$ e enviadas aos usuários administradores a fim de validar tais novos registros.

Segundo Santos, Tedesco e Salgado (2011) a representação conhecida como Framework $5 \mathrm{~W}+1 \mathrm{H}$ identifica seis questões básicas que, ao serem respondidas, auxiliam o 
usuário a compreender algo do qual não tem conhecimento prévio. Esse framework é caracterizado pelas perguntas: Quem (Who), O quê (What), Onde (Where), Quando (When), Como (How), Por que (Why). Tais perguntas facilitam a assimilação das informações de percepção disponibilizadas para os usuários.

Um exemplo de história utilizando esta representação: Quem: Fulano; O quê: Inserção de nova palavra; Onde: Dicionário; Quando: Hoje; Como: Formulário; Por que: Incrementar o número de sinais. Diante disso, a percepção é alcançada após os usuários administradores receberem essa história, processar a requisição, compreender as informações e submeter a confirmação para a ferramenta.

\section{Requisitos e Casos de Uso}

A ferramenta proposta possui em sua concepção requisitos funcionais e não funcionais. Os requisitos funcionais inicialmente elencados são: colaboração (seguindo o modelo supracitado) na forma de (i) contas com funções de usuário comuns ou administradores; (ii) sistema de ranking de notas para os termos, a fim de demonstrar o grau de confiabilidade desses; (iii) todos usuários têm permissão de votos em perfis/termos; (iv) permitir denúncias de todos termos registrados, assim como de usuários, sendo essas denúncias revisadas por contas administradoras; (v) ranking de colaboração por usuários (gamificação); (vi) verificação de contas com base em alto ranking/participações em denúncias; (vii) dicionário orientado à busca por palavras; (viii) criação, edição e denúncias geram pontos para o usuário conforme grau de importância; (ix) cada palavra possui um histórico de colaboração por nomes de usuários.

Além da colaboração, o sistema inclui como campos do dicionário as principais definições para a palavra buscada, como: (i) palavra; (ii) regionalismo; (iii) mão; (iv) sinal em vídeo (integração com vLibras); (v) acepção; (vi) exemplo em português e exemplo em Libras; (vii) assunto; (viii) imagem; (ix) parâmetros primários de Libras (ponto de articulação, configuração da mão); (x) parâmetros secundários de Libras (disposição e orientação da mão, região de contato).

Diante disso, pode-se criar casos de uso a fim de detalhar como os requisitos serão utilizados na prática. A seguir são demonstrados dois fluxos possíveis do sistema, o primeiro com utilização por um usuário comum que gostaria de registrar uma nova palavra, e o segundo com utilização de um usuário administrador que removerá uma palavra com baixa nota.

1. (i) usuário registra-se no site; (ii) usuário busca a palavra e verifica que ainda não existe; (iii) usuário vai para a página para criação de uma nova palavra; (iv) usuário preenche o formulário de requisitos; (v) usuário envia palavra e espera aprovação do usuário administrador.

2. (i) usuário administrador procurar por palavras com baixo ranking; (ii) usuário administrador entra na página da palavra; (iii) usuário administrador confirma a remoção da palavra.

Isto exposto, consegue-se obter uma visão geral da arquitetura planejada para a ferramenta e formas de utilização tanto por usuários comuns e usuários administradores, não sendo limitado apenas por essas apresentadas. 


\section{Considerações Finais}

O presente trabalho visa beneficiar a comunidade surda, favorecendo a inclusão de novos aprendizes de Libras, por meio da criação de um dicionário de sinais que contemple o regionalismo e aprendizado da gramática de Libras através de um ambiente de colaboração. O dicionário propõe-se a estimular o ingresso de novos aprendizes, bem como consolidar o conhecimento de falantes de Libras.

Parte da presente pesquisa foi submetida ao comitê de Ética sob o protocolo no 87266318.6.-0000.0118. Contudo, ainda serão necessárias algumas adaptações para avaliação da ferramenta com a participação do público surdo.

\section{Referências}

COSTA, S. da et al. ilibras como facilitador na comunicação efetiva do surdo: uma ferramenta colaborativa móvel. In: Anais do XIV Simpósio Brasileiro de Sistemas Colaborativos. Porto Alegre, RS, Brasil: SBC, 2017. p. 95-109. ISSN 0000-0000. Disponível em: 〈https://sol.sbc.org.br/index.php/sbsc/article/view/9953〉.

FREITAS, L. E. R. de; BERKENBROCK, C. D. M.; SELL, F. S. F. Incorporação de aspectos de colaboração no dicionário da língua brasileira de sinais: uma análise da viabilidade. In: SBC. Anais Principais do XV Simpósio Brasileiro de Sistemas Colaborativos. [S.1.], 2019. p. 13-17.

FUKS, H. et al. Teorias e modelos de colaboração. 2011.

LIRA, G. de A.; SOUZA, T. A. F. de. Dicionario da Lingua Brasileira de Sinais V3 2011. 2011. Disponível em: 〈http://www.acessibilidadebrasil.org.br/libras \_3/〉.

MOURA, E. R. da S. Uma ferramenta colaborativa movel para apoiar o processo de ensino-aprendizagem da Lingua Portuguesa para alunos surdos. Dissertação (Mestrado)

— Universidade Federal do Amazonas, http://tede.ufam.edu.br/handle/tede/4069, 3 2015.

OLIVEIRA, R.; MARQUES, R. R. USO DA VARIACAO LINGUISTICA NA LINGUA BRASILEIRA DE SINAIS. 1. ed. [S.1.: s.n.], 2014. v. 2.

SANTOS, V. V. dos; TEDESCO, P.; SALGADO, A. C. Percepção e contexto. 2011.

STOCK, I. M. Lingua Brasileira de Sinais. 2018.

STROBEL, K. As imagens do outro sobre a cultura surda. 4. ed. [S.1.]: UFSC, 2016. ISBN 9788532807786.

SUITE VLibras. 2017. Disponível em: 〈https://softwarepublico.gov.br/social/ suite-vlibras $\rangle$.

VENTURA, L. A. S. Aplicativo ensina termos de educação profissional em Libras. 2021. 〈https://brasil.estadao.com.br/blogs/vencer-limites/ aplicativo-ensina-termos-de-educacao-profissional-em-libras/ $\rangle$. 